\title{
A unique space for different religions?
}

\author{
Marta Averna \\ Politecnico of Milan, Dastu department
}

\section{Keywords}

Interfaith; Chapel; Light; Interior architecture.

\begin{abstract}
Architecture makes room to life; it hosts the gestures of a single human being or of a group and translates them in material forms, made of space, margins and equipment. Architecture's hosting ability is clarified and tested in its limits, by its physical features. This ability is stressed in contemporary society, made of moving communities, gathered more around a shared need (study, work, research of wellness conditions) than around a rooted tradition. In them identity-making features, like the beliefs on Divine and Universal, can be forced to coexist. Men's relationship with Transcendent is structured on successive levels: the meditation, silent and private, the prayer, also in small groups, and the rite, collective and organised. If the first is independent from credo, and sharable in quiet rooms, the two following are much more identity related, and they are absolutely difficult to be placed side-by-side. Traditional communities have specific places and modes for all these levels, contrary to newly built communities, looking for new spaces, able not to divide different credo, but to relate them maintaining their differences. Detailed design, the closer to the gestures of dwellers, clarifies the call of this spaces, in the attention paid to materials and finishing, demonstration of their dignity, in the design of equipment, able to suggest with small variations mutual superimpositions or divisions, in the relationship with light, hidden or direct, but always sign of Divine, in the presence of the work of art, often abstract or defined by the light, natural or artificial, and by the openings on the outer, surrounding world. A longlasting work of research, on case studies and their theoretical basis, and a design experimentation, carried on during Architecture of Interiors Studios in Politecnico di Milano, explore the possible coexistences, through the material forms of architecture.
\end{abstract}

\section{1_A declaration of intents: MIT Chapel and interfaith spaces}

The MIT Campus in Boston, built along the banks of the Charles River, is characterized by a stratified fabric with a green square surrounded by trees. On one side of the square, a cylindrical volume of bricks in a circular water basin interrupts the orthogonal grid of the structure ${ }^{1}$. The irregular bricked face rises over the water with a series of flounces, like a gown, leaving the reinforced concrete structure in sight, while a translucent tunnel passes through the basin, creating the entrance (Figure 1). Double light-colored wooden doors along the sides allow to pass from the wide, luminous, treed space of the square to an elongated corridor, closed by translucent or colored large windows, progressively moving away from the whirl of everyday activities. A second series of wooden doors leads to a centric continuous space, closed by an undulating brick face, almost resembling a cloak. There are no windows: the light reverberates in the lower part of the structure through hidden openings that capture the light arriving from the water basin. In the upper part, instead, the light is refracted from the specks of a large sculpture by Harry Bertoia ${ }^{2}$, a mobile, onto which it arrives passing through the covering skylight (Figure 2). It is a warm and welcoming space that envelopes those who enter, separating them from their everyday life, although keeping them connected. It is a space that allows to look at the sky, without losing contact with the world.

MIT's chapel was designed in 1955 by Eero Saarinen. It is not a confessional, and it is open to all the beliefs present on Campus. It is currently managed by 25 chaplains representing 40 groups of students, gathered in a religious

1 Eero Saarinen, MIT Chapel, MIT Campus, Cambridge, Boston, Massachussets, dedicated in 1955 (Saarinen \& Saarinen, 1968)

2 Harry Bertoia, Floating Screen, Cambridge, Boston, Massachussets, 1955 (Kompass Nelson, 1970) 
belief. ${ }^{3}$ A specific institution, the ICEO, Institute Community and Equity Office, takes care of diversity and equity, with the mission to advance a respectful and caring community that embraces diversity and empowers everyone to learn and do their best at MIT. ${ }^{4}$

Its architecture and interiors, although allowing everybody to feel welcomed and free to profess their deepest beliefs in total freedom, are not white and silent with the idea to welcome differences. On the contrary, they are connoted in a way that in every language and modality talks about the relationship with what is sacred and transcendent.

Aim of this paper is exploring, through the analysis and the description of contemporary case studies, realized from the second half of last century, the features of architecture and interiors devoted to host people different in their deepest beliefs. Two ideas subtend this text: the first is that architecture have the social responsibility to face the questions posed by contemporaneity, and among them diversity, trying to understand, interpret and make them comprehensible, and the second is that the form is the mean through which this interpretation and donation of sense is told. The paper will first explore the relationship between form and meaning in the specific and complex case of beliefs, and the variations caused to architecture and its interiors by those in the number of users (single person, small group, big group) and in the quality of the gestures carried on (meditation, prayer, rite). Then it will analyze some realized case studies to explore some significant material features: the relations of these spaces with the surrounding environment (insertion/separation), the role of the light and of the works of art, and the possibilities given by the distribution and the flexibility of rooms and spaces.
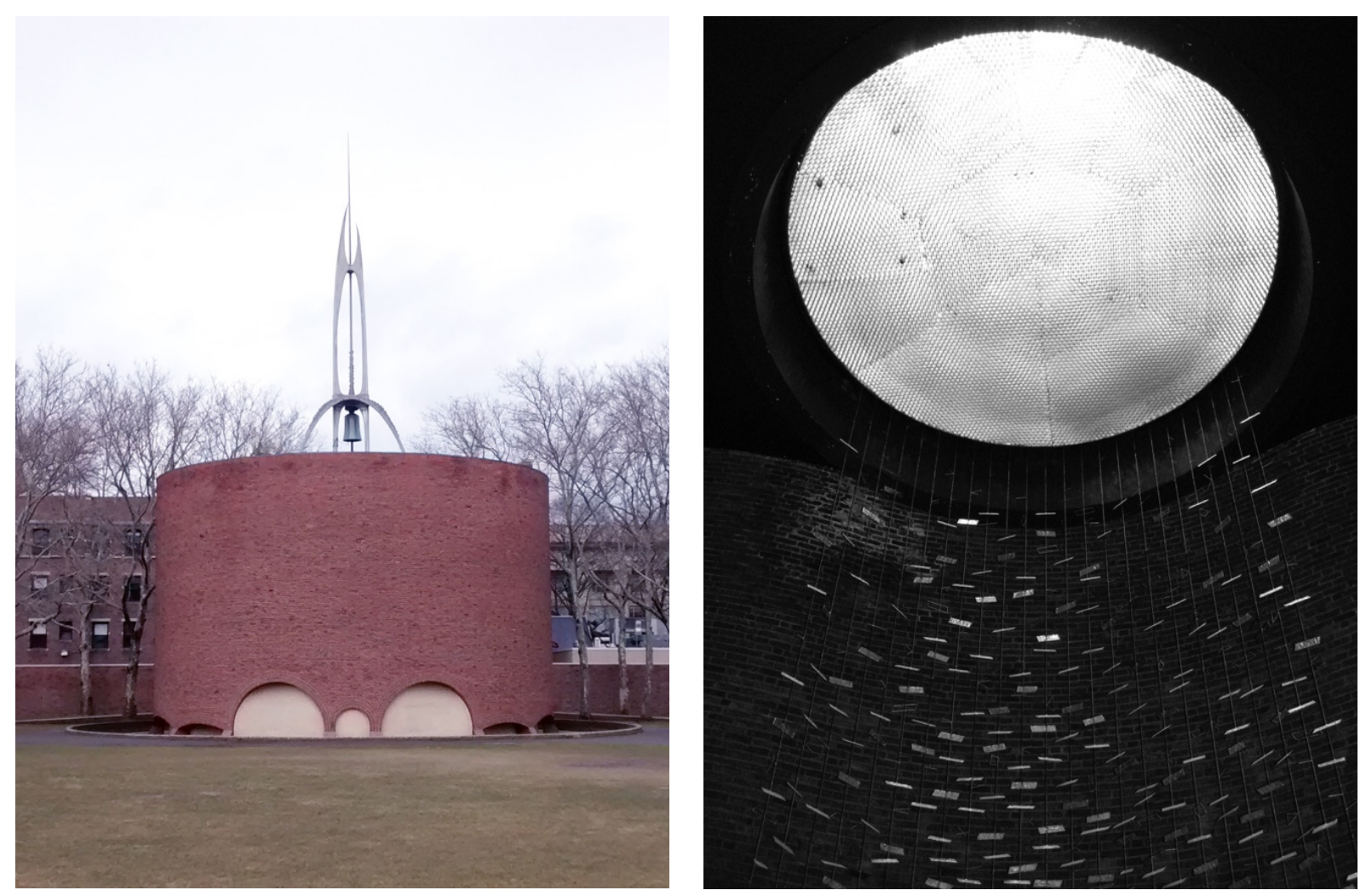

Figure 1: The outer view of the Chapel shows the irregular brick façade rising over the round water pool, letting the concrete structure on view. The cylindric volume is completed by the aluminum Bell tower, realized by Theodore Roszak. (Leonel Ponce, www.bit.ly/2xaKN6j)

Figure 2: The core of the Chapel is highlighted by a reredos, a mobile designed by Harry Bertoia. It is made of light metal specks, hanged to the ceiling, moving in the air and playing with the light coming from the skylight standing above. (Gunnar Klack, www.bit.ly/2xbrwS9)

$3 \mathrm{http}: / /$ studentlife.mit.edu/rl/who-we-are

4 http://diversity.mit.edu 


\section{2_ Diversity and proximity in the forms of architecture}

The architectural forms play a fundamental role in defining and guaranteeing this sense of freedom to welcome believers. In fact, these forms have the inherent ability to suggest a use, a possible behavior: in a small room one does not say what one would in a large room, as Louis Kahn stated in $1971 .{ }^{5}$ As in every art, the form of things carries their meaning, in a substantial identity between signifier and significant. ${ }^{6}$

Louis Kahn defined architecture as follows: Architecture is the thoughtful making of spaces. It is the creating of spaces that evoke a feeling of appropriate use. (Kahn, 1960) The adjective used, appropriate, perfectly describes the ability to make everyone feel at home, and have a fruitful reaction toward the world; in other words, to dwell it, recognizing and understanding its own rules and way of working. (Norberg-Schulz, 1985)

The ability to welcome believers is a challenge for all heterogeneous communities: the presence of different experiences and traditions makes communication and cohabitation complex. Over the history, the closeness between different ways of meaning life often caused tensions, and even wars: we can also remember situations in which the cohabitation was researched and enhanced, as in the so called Convivencia in Spain. In Cordoba, among the IX and the X Century, Christian and Jews were involved in the intellectual life and in the Muslim Royal Court.

The occasions of cohabitation increasingly grew up during the XX Century, because of migrations and of major possibilities to move through the planet for different reasons. They concern both everyday life (families migrating for work reasons, aiming at establishing new roots in a new country) and unusual and temporary occasions (people travelling, or moving for study reasons, taking part to temporary events related to sport, trade, politics, or even obliged to a long stay in a hospital, or a prison). (Rizzi, 2019)

Complexity can reach such high levels to make cohabitation impossible, if one of the cultures deems itself overriding, more correct, or dominant compared to the others; or it can make cohabitation difficult, if the non-shared traits are deeply related to identity, such as in the case of religion, and if the will and ability to dialogue are scarce or not much cultivated. It is necessary to establish a dialogue, codifying a grammar (Sorrentino, 2007) that allows heterogeneities to be open and willing to see and understand what is new and different, overcoming places and ways codified by history in order to weave a fabric of fruitful relationships also in communal life.

As mentioned, the characteristics of the place in which dialogue takes place play a fundamental role in fostering said dialogue. Indeed, this place becomes the symbol of communication, a bridge connecting differences, in cultures, or in worlds, as in the case of man and the divine. All the elements of architecture act a role in this play: that is margins (horizontal or vertical, natural or built by men, with their features related to construction and finishing materials and techniques), giving a shape to the space (considered not as a void, but as a substance with its material features, such temperature, color, light, ...) and equipped by furniture (built in or movable, integrated or recognizable, always with their material features) (Ottolini, 1997).

Some sacred spaces deeply changed their use during the centuries, proving their capability to speak of God in different languages and in different religions. The current Cathedral of Cordoba was built from the 784 as a Mosque and reconverted as a Church only in 1236, after the Reconquista. In 2004 Mansur Escudero, Secretary General of the Spanish Islamic Council asked the Pontifical Council for Interreligious Dialogue the permission to make Christian and Muslim pray together, in this potentially sharable space: the still existing mihrab is the peripheral to the main axis of the Cathedral, so the two groups of worshippers wouldn't bother each other. The request, even if considered reasonable, didn't lead to any change in the use of the Cathedral, due mainly to practical reasons, as the conservation of an existing balance between the different religious communities. (Russo, 2007)

As it would be in this, never realized example, space is to be understood not as a separation that divides, but as a delimitation that symbolically joins diversities: (Tagliaferri, 1995) this is the only way in which we will be able to experience dwelling as "the way in which mortals are on the earth." As highlighted by Heidegger, the crisis depends on the lack of roots, due to which men "first have to learn how to live." (Tagliaferri, 1995), and architecture can become the medium through which this gets visible and understandable.

5 Louis Isidore Kahn, Architecture Comes From the Making of a Room, 1971. Philadelphia Museum of Art, Gift of the artist.

6 "However, in any other intersubjective communication, the so-called "two faces" of any sign, the signifier or material vehicle of the signified, and the meaning or cognitive content associated with it are not of the same nature, one being physical reality and the other mental reality; although it is true that in art the signified does not only presentify in the mind of the subject producing or "listening to" the work, but is inscribed in the signifier itself by specific constitutional means." (Ottolini, 1997) 


\section{Gestures and users: from individual to groups, from silence to rite}

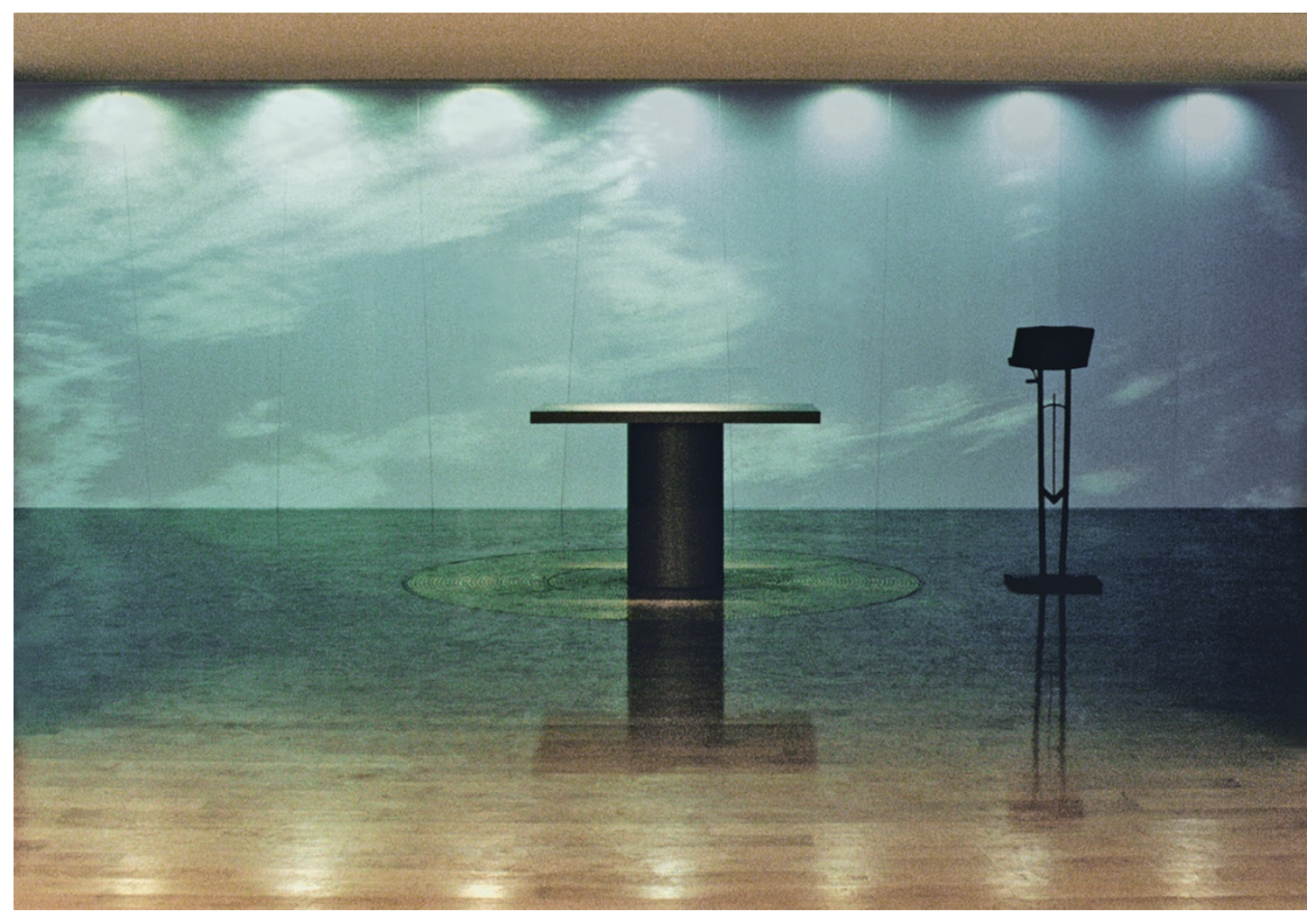

Figure 3: The light scenery flat of the Malpensa Airport Chapel, with his drawing of clouds on a blue sky background, reflects on the pavement, changing its color and its perception (Laura Viale, Glass wall of Malpensa 2000 Airport multi faith chapel, Milan, 1998, digital print on transparent film on backlit glass, 3 x 10 m, chapel design by Ettore Sottsass)

The relationship between man and God is translated in different ways: there is the silent and meditative way of the single individual; there is the organized prayer for small groups; and lastly, the deeply structured acts of collective rites. In traditional communities, members recognize themselves in a single religion and the entire community knows the rules and correct places for each moment. Moreover, each place is so structured that it is extremely complex for it to open up to experiences different from those for which it was designed.

However, silent and private meditation can be carried out more easily in shared environments, not specific to a given religion: this is evident in the case of quiet rooms present in airports, train and bus stations, places characterized by heavy transits connected to the transport system, as well as in hospitals and places devoted to care services. Placed along the main paths to enter and move in these centers, the quiet rooms are detached owing to their introvert form and to the design of their access paths, that move away from the fast movement of the means of transport or the suffering in hospitals. Ettore Sottsass designed a Chapel for the Malpensa ${ }^{7}$ airport that has a separate access, although near the hall of the departure floor, reachable through a narrow corridor characterized by blue mosaic walls. It opens to a rounded anteroom, giving access to the higher space of the chapel. This space, hidden and totally introvert, points at a light scenery flat, always blue (Figure 3), causing to leave the self behind and go beyond the physical space. ${ }^{8}$

However, the continuous movement of recently founded communities due to work, study, participation in events of excellence, such as sport events, has led to the need to face a new challenge: that is, to share places that are more structured than those destined exclusively to silence and a personal experience. During Olympic Games of 1992, the Archbishop of Barcelona promoted the construction of an ecumenical and interfaith center, ${ }^{9}$ following the

7 In the original project for the first big enlargement and adaptation to international standards of Malpensa airport, Mario Botta designed an ecumenical chapel, never realized. Ettore Sottsass designed the interfaith chapel here described, newly set up in a short time as a Catholic chapel, the of the Madonna di Loreto of Malpensa Airport.

8 The glass wall has been realized by the artist Laura Viale, overlapping a picture of a barely veiled by clouds sky (Cielo n. 42, 1997) to light sources, creating a feeling of big peacefulness.

9 Josep Benedito, Agustí Mateos, Centro Ecuménico Abraham, Barcelona, Spain 1992. After the end of the Olympic games, the Centre has been transformed into a Catholic Parish. 
indications of the International Olympic Committee, who recognizes five faiths (Protestantism and Catholicism, Islam, Buddhism, and Judaism) and provide them houses for worship. The Abraham Centre has an elongated plan, connected by a large stair, leading from the level of the square to the one of the chapel (Figure 4). The elliptic chapel alternate full height and lower spaces, as entrances and balconies, naturally lit by big windows. The core is identified by a wooden elliptic false ceiling and points at a work of art, three golden bowls on a white background, symbolizing the three monotheistic faiths.

As soon as we discuss of sharing spaces devoted also to rites, the ground becomes suddenly steep. To define religion is a complex task, as often it involves aspects that are not strictly religious in themselves. This is the case, for example, when having to define what is authentic and what not, or religion's relationship with ethics, laicity, or power. As stated by Altan, the deep symbolism of a peoples' identity is rooted in religion. (Altan, 2002) Besides, religions often describe themselves as the founding element of a new civilization, overcoming a previous unpopular and unfair order.

A first step toward recognizing that all citizens of a same state are equal consists in accepting the equal dignity of the different religious beliefs. Surprisingly, one of the first bodies that promoted the construction of interdenominational or ecumenical chapels was the United States' army, in the mid 1900s. In fact, between 1958 and 1968, SOM designed the United States Air Force Academy Cadet Chapel, ${ }^{10}$ in Colorado Springs (Figure 5). Drawing inspiration from the Parisian Sainte Chapelle, the chapel's design provided for a double pitched roof, with an extremely steep inclination (Figure 6). The overall structure is organized as follows: the Protestant chapel is placed on the upper floor, the Catholic one on the ground floor, while the synagogue is on the underground floor. The three deeply different spaces stay side by side, and they aren't interconnected. ${ }^{11}$

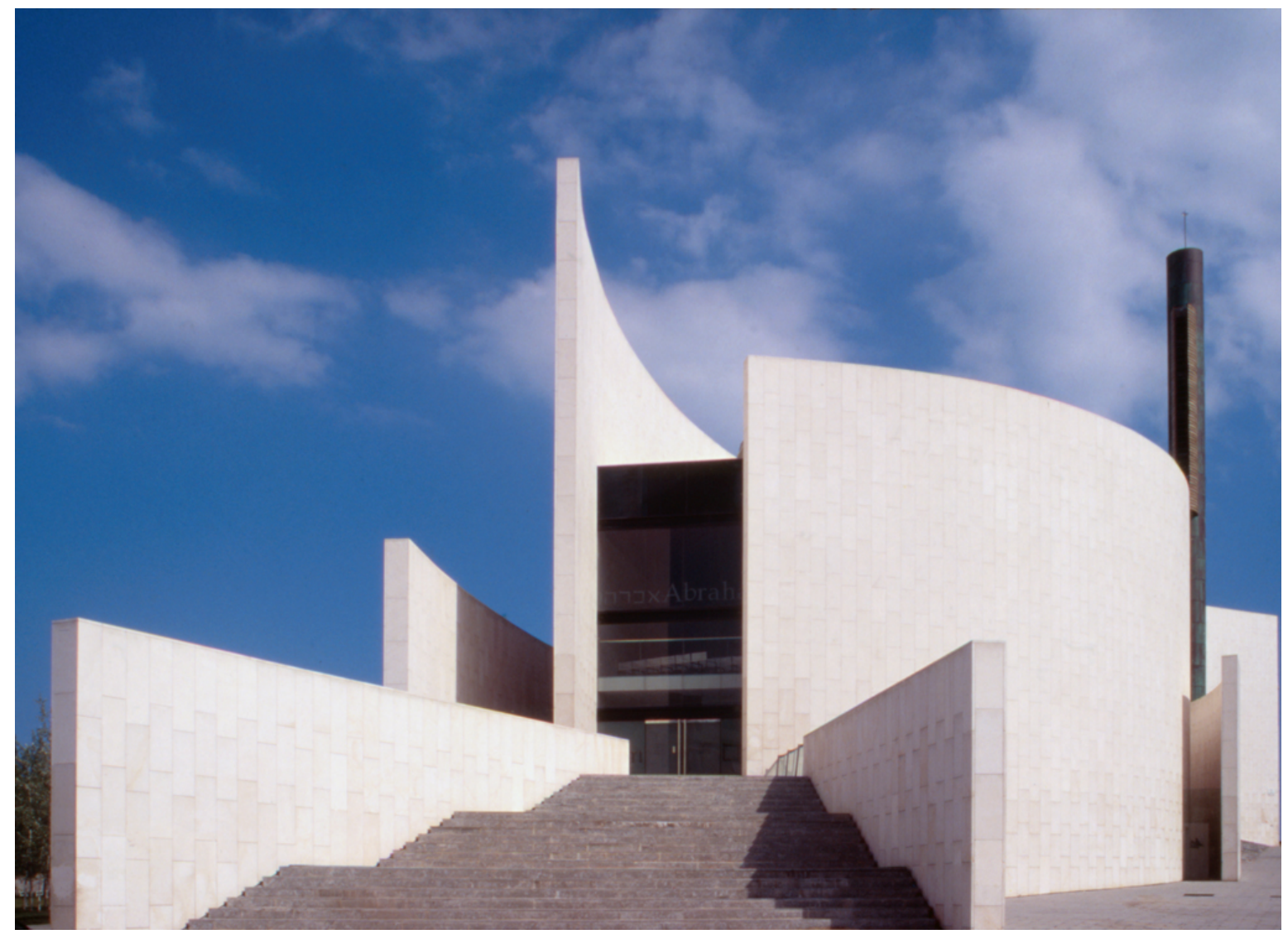

Figure 4: The main façade with the long stair leading to the Centro Ecuménico Abraham, in Barcelona, showing the high white walls protecting the shared chapel. (Robert, www.bit.ly/320g1eJ)

10 Walter Netsch, SOM (Skidmore, Owings \& Merrill), United States Air Force Academy Cadet Chapel, Colorado Springs, Colorado 195868. (Powers, 1974)

11 In 2007 a Buddhist chapel was realized as freestanding hall within the Cadet Chapel; in 2011 the Falcon Crest, an open air space defined by an enclosure of big stones, was designed for "The Earth Centered Spirituality" group. The All-Faiths Rooms, worship areas for smaller religious groups, purposely devoid of religious symbolism. 

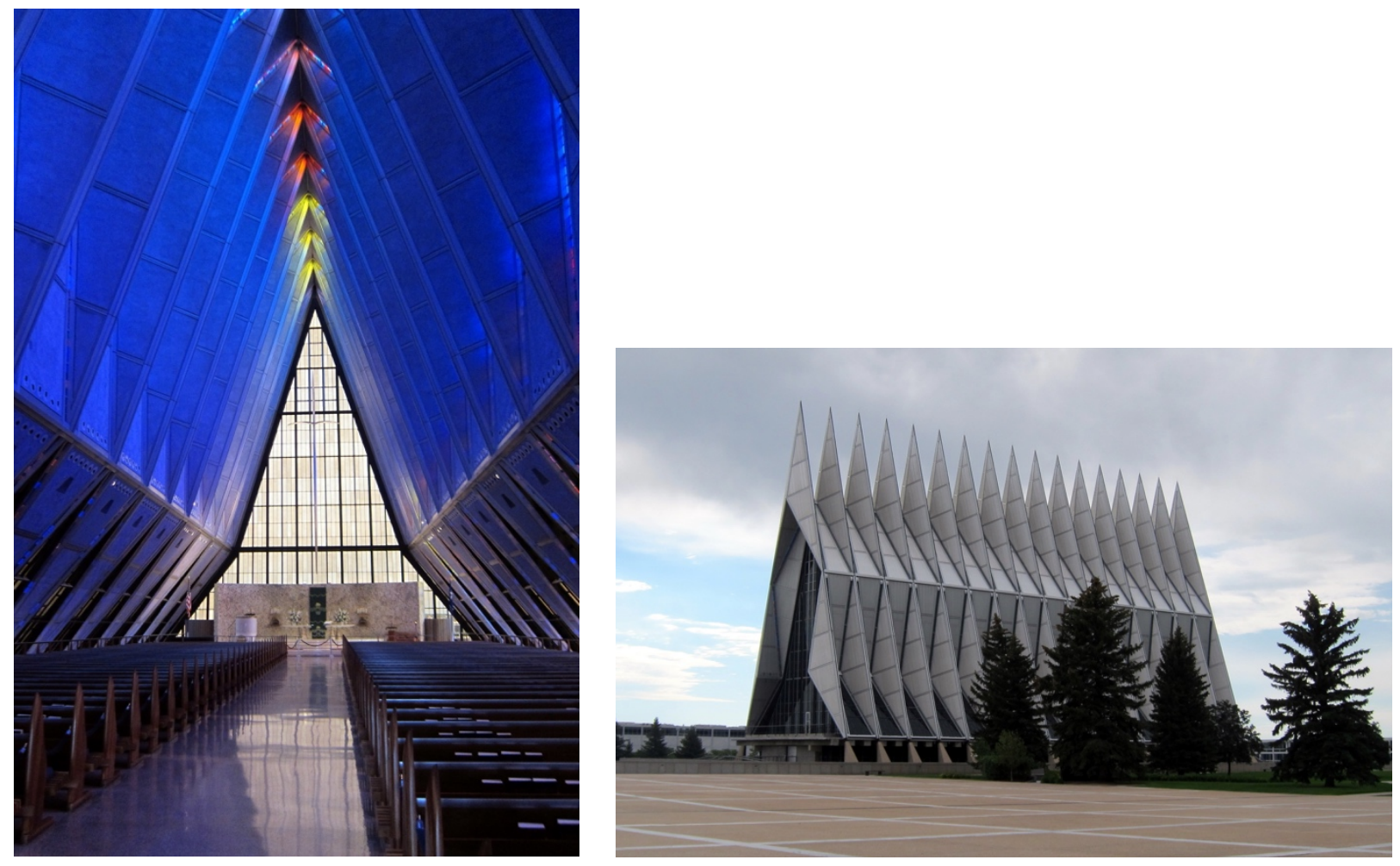

Figure 5: An interior view of the Cadet Chapel, showing the different effects given bay natural light passing through the colored glass walls: the white, neutral light behind the main altar, and the colored one, red, blue, and yellow, over the benches for the worshippers. (Wally Gobetz, www.bit.ly/320ilCt)

Figure 6: The outer volume of the Cadet Chapel is defined by 17 extremely steep ribs, folded by a white metal plate. Between them, not so visible from the outer square, stay the colored glass walls. The inner part of the Chapel, and all its levels, id (Wally Gobetz, www.bit.ly/2XcreoB)

When designing a sacred space, the architectural challenge is to understand how to reinvent some characteristics deemed unavoidable, with the aim to translate them into new forms. Moreover, the new forms have to be equally dense in meaning, and at the same time sharable, thus capable of giving up any symbols that are too evident, or a figurative decoration that can be misunderstood. It is necessary to learn how to design a space which, in its most intimate essence, symbolizes the relationship between man and God. Therefore, we investigated this theme through research and didactics, with the aid of the students of the School of Architecture of the Politecnico of Milan, in the Architecture of Interiors Design Studios. Already existing solutions were explored and new buildings were designed, often imagined within the University Campus. ${ }^{12}$

In interior architecture it is particularly interesting to pay attention to gesture, as it is a function dense of meaning that is not only operational - of man dwelling the space - to the formal quality of architecture understood as a complex structure ${ }^{13}$ organized as a whole and as a detail in a very close up scale. Indeed, the fundamental idea is the kahnian one according to which nothing works, until everything works, (Gattamorta, Rivalta, \& Savio, 1996) in a continuous transition among scales and their mutual fallouts.

\section{The context: insertion and separation}

One of the themes that needs to be faced and translated into form when designing these buildings concerns the relationship with the world, taking into consideration both insertion and separation. The new sacred places have to be recognizable and become part of an urban or natural context. At the same time, they have to abstract themselves from their context, in order to recall something that innerves and at the same time transcends them. When they are recognized as the sacred space shared by a close community, as the SOM Chapel, they become a center on which

12 Bibliographical researches, analysis, projects were developed by the students of the Laboratorio di Progettazione dell'Architettura degli Interni, during the Academic Years between 2005-2006 and 2008-2009, held by me and professors Roberto Rizzi, Stefano Levi Della Torre, Lukas Janisch, with the help of the architects Aurelia Belotti, Ilaria Guarino and Fabiano La Rocca, and by several graduands.

13 "In line with the above-mentioned laws of Gestalt, Biagio Garzena has spoken of form as an "integral" (in the mathematical sense); that is, as a fusion and not merely the summation of multiple elements or characteristics of constitutional aspects." (Ottolini, 1997) 
citizen can orient themselves through the urban fabric, able to give it a deeper meaning. The Cadet Chapel catalyzes the Academy space, unique high, vertical volume in the horizontality of the school, and unique one without windows on its sides; the Kresge Chapel stands alone, protected by water, in the middle of a square, clearly with a different call compared to the rest of the M.I.T. Campus: collective, public, common.

Some other case studies suggest a double possibility of continuity and donation of a sense to the built landscape, and of separation from everyday life difficulties, earning a meaning in themselves. The quiet room realized in the Salam Centre for Cardiac Surgery in Khartoum ${ }^{14}$ - designed by the studio TAM Associati in 2007 for Emergency - is formed by two staggered rooms enveloped, with a continuous movement, by a high white wall. Acting as a hinge, a walkway in-between the two rooms passes through - barely above the water - a squared water basin giving it access. The prayer room is hidden by walls, protected by water, screened through its rush matting covering. The room develops on a side of a vertical cut that gives it access. It is protected from sight, it is lined with a reed matting. In a corner of this room - a place created to mitigate pain and waiting time - life is emphasized through the presence of a tree, sign of the relationship with heaven and the divine.

A sacred place [...] is a symbolic bridge joining heaven and earth. It materializes when the sacred architecture creates the appearance of the other world that is the counterpart of the I and us and a place where the familiarity inherent a house has to coexist with expropriation and non-involvement in order to sense the presence of the other. (Tagliaferri, 1995)

\section{Man and the Divine: light and works of art}

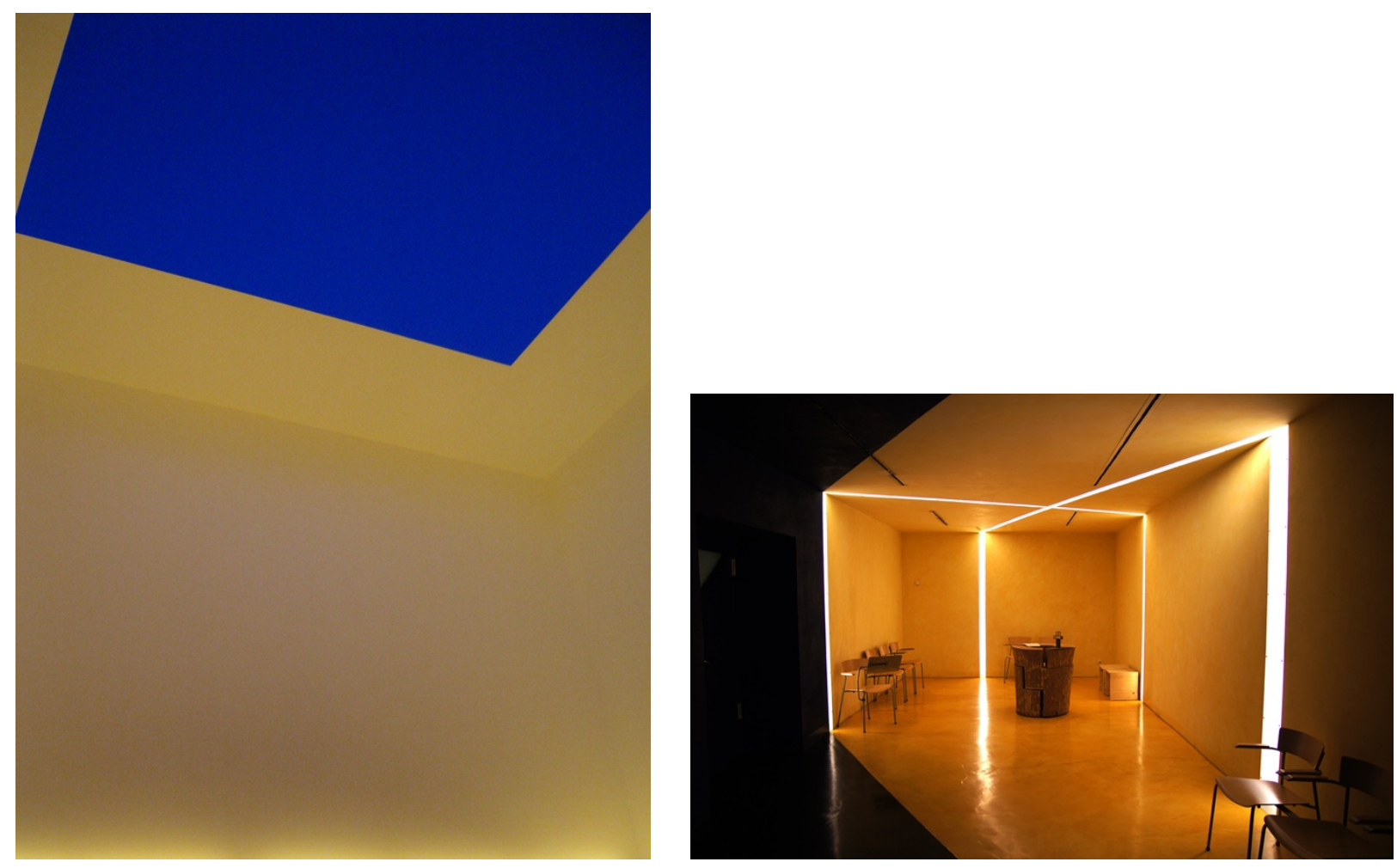

Figure 7: James Turrel, Meeting 1989. One of the skyspaces realized by James Turrel, in which artificial and natural light work together to change the perception of the space. (Ray Weitzenberg, www. bit.ly/2XwZGPe)

Figure 8: The inner space of the Tag\&NachtRaum designed by Werner Mally for the Städtisches Klinikum of MünchenHarlaching, in which light and finishing materials define the quality of the space (Tobias Schneider, http://bit.ly/3cNpuLG)

Indeed, the use of light is never neutral: it is used as the fundamental material of a piece of art, straddled between architecture and the environmental installation. It exploits different qualities and variation possibilities through the use of natural and artificial sources.

14 TAMassociati, Prayer and meditation pavilion for Salam Centre for Cardiac Surgery, Khartoum, Sudan 2007, Aga Khan Award for Architecture2013 winner. (Serrazanetti \& TAMassociati, 2017) 
Some elements of architecture have the responsibility more than others to build a relationship between two presences, a visible one and a slightly veiled one beyond the ordinary perception. One of these elements is light, as it symbolizes the attempt to tend toward God, emphasizing the heart of the rite. The Cadet Chapel in Colorado Springs is characterized by windows along the ribs of the steep covering, through which a warm blue light in the lower part and a red light in the higher one, that tends to the vertical of the axis mundi, filters in directed toward the lower part of the chapel. All this is opposed to the white milky light coming from the opal windows behind the altar, a neutral basis for the celebration. ${ }^{15}$

This is what occurs in James Turrel's installations designed for sacred spaces, often confessionals, where the light emphasizes the color and meaning of a space outside of time, putting it by contrast in relation with the time, told by the quality of the light with the passing of hours and seasons. ${ }^{16}$ The author said he was interested in the sense of presence of space; that is space where you feel a presence, almost an entity (Haskell \& Wortz, 1980), the relationship between something contingent and something absolute. In the Live Oak Friends Meeting House, Turrel realized in 2000 One Accord, a skyspace, that is a specifically proportioned chamber with an opening in the ceiling open to the sky. The rectangular opening in the barrel vault of the Chapel, can be opened to show the sky, or can simulate it with the use of blue, pink and red neon tubes, put around it and on the abutments of the vault (Figure 7).

As light, works of art play an outstanding role in defining the identity of sacred spaces, as historical examples show in precise and diverse ways: in confessional spaces they can be figurative or not, but in any case, they highlight the cores of the rites, the pace of celebrations, the separation/connection with everyday life.

This way can be analyzed alongside the Rothko Chapel in Houston, ${ }^{17}$ realized around 14 monumental canvases by commission of John and Dominique de Menil. The interior of the building, a brick irregular octagon inscribed in a Greek cross, is a void space, surrounded by the works of art, receiving light only from a baffled skylight: a suspended space, equipped only by eight movable benches, open to host all believers and support them in prayer.

The connection between ground, human, ordinary and sky, divine, extraordinary is often highlighted by inner and outer work of art: the MIT Chapel is completed both inside by the sparkling Harry Bertoia's reredos, and outside from the aluminum Bell Tower, realized by Theodore Roszak in 1955. (M.I.T. Chapel and Spire, 1955), and the Centro Ecuménico Abraham on the one hand by the bell tower and on the other one by the white panel supporting three golden bowls, recalling the traditional Jewish history of the three golden rings, symbol of the three Abrahamic religions, included in several Italian medieval collections of short histories and especially in Boccaccio's Decameron. ${ }^{18}$ (Boccaccio, Decameron, 1470).

In year 2000, the Czech artist Werner Mally designed Tag\&NachtRaum, providing it with a luminous diagonal cross that passes through the walls and the ceiling, straddled between an extended field of luminous yellow stucco, and a corner in-between two walls made of dark blue stucco. ${ }^{19}$ (Figure 8).

15 At the ground floor the Catholithic Chapel is lit by amber windows, and in the underground the Synagogue is closed by coloured glass slabs on cypress frames.

16 Among the installations for sacred spaces realized by James Turrel, we can remind, apart from the one for the Houston's Live Oak Friends Meeting House, built in 1995, the one for the Church Santa Maria Annunziata in Chiesa Rossa in Milan. This was designed in 1996, the year of the death of the artist, and ended after his death. Neon tubes follows the contour of the barrel vaults and of the apsidal conch: green, blue, pink and golden lights change deeply the perception of the space.

17 Philip Johnson, Mark Rothko (paintings), Rothko Chapel, Houston, Texas 1962. (De Menil, 1971)

18 I remember often to have heard of a great and rich man, who among his most rare and precious jewels, had a ring of exceeding beauty and value. Being proud of possessing a thing of such worth, and desirous that it should continue for ever in his family, he declared, by will, that to whichsoever of his sons he should give this ring, him he designed for his heir, and that he should be respected as the head of his family. That son to whom the ring was given, made the same law with respect to his descendants, and the ring passed from one to another in long succession, till it came to a person who had three sons, all virtuous and dutiful to their father, and all equally beloved by him. Now the young men, knowing what depended upon the ring, and ambitious of superiority, began to entreat their father, who was now grown old, every one for himself, that he would give the ring to him. The good man, equally fond of all, was at a loss which to prefer; and as he had promised all, and wished to satisfy all, he privately got an artist to make two other rings, which were so like the first, that he himself scarcely knew the true one. When he found his end approaching, he secretly gave one ring to each of his sons; and they, after his death, all claimed the honour and estate, each disputing with his brothers, and producing 24 his ring; and the rings were found so much alike, that the true one could not be distinguished. To law then they went, as to which should succeed, nor is that question yet decided. And thus, it has happened, my Lord, with regard to the three laws given by God the Father, concerning which you proposed your question: everyone believes he is the true heir of God, has his law, and obeys his commandments; but which is in the right is uncertain, in like manner with the rings. (Boccaccio, Decameron or ten days' entertainment, 1855)

19 Werner Mally, Tag\&NachtRaum, Städtisches Klinikum München-Harlaching, Münich 2000 (Zahner, 2004) 


\section{Adapting spaces: the role of flexibility}

Flexibility can be another key to design a sharable sacred space. The possibility to welcome different communities that gather to pray and carry out different rites requires the presence of an equipment that must not be too pervasive and at the same time needs to be flexible in its use, easily adaptable to different users and expectations.

The Interfaith Spiritual Centre in Boston, a rectangular and elongated space, is designed on the number three (Figure 9). The space, artificially lit on three sides, is phased in three following spans, characterized by three concentricdesigned hanging canopies. They highlight the three monotheistic religions to which the space refers. There are few pieces of furniture that can be moved or closed, enabling the space to be used while sitting, standing, looking in various directions and in variously organized liturgies. ${ }^{20}$

Furthermore, partitions can be rotated, folded or moved to create new configuration of spaces, smaller or bigger, inner or outer, private or shared, answering to the need of different groups of users, and to the exigences of prayer or rites.

The ecumenical Maria-Magdalena-Kirche, ${ }^{21}$ built in Freiburg between 1998 and 2006, is a concrete monolithic volume, formed by three naves. The two side ones host two different churches: the western nave a Catholic church and the eastern one a Protestant church (Figure 10). Their mood is different: if the first is contemplative, lit by few openings, the second is bright and lively, thanks to a big opening facing East. Among the two, a central foyer in which the baptismal font stays. Eight-meter-high sliding concrete walls allow the three part to be joined together for the ecumenical services, creating a unique hall unified by the timber beams of the ceiling (Figure 11).

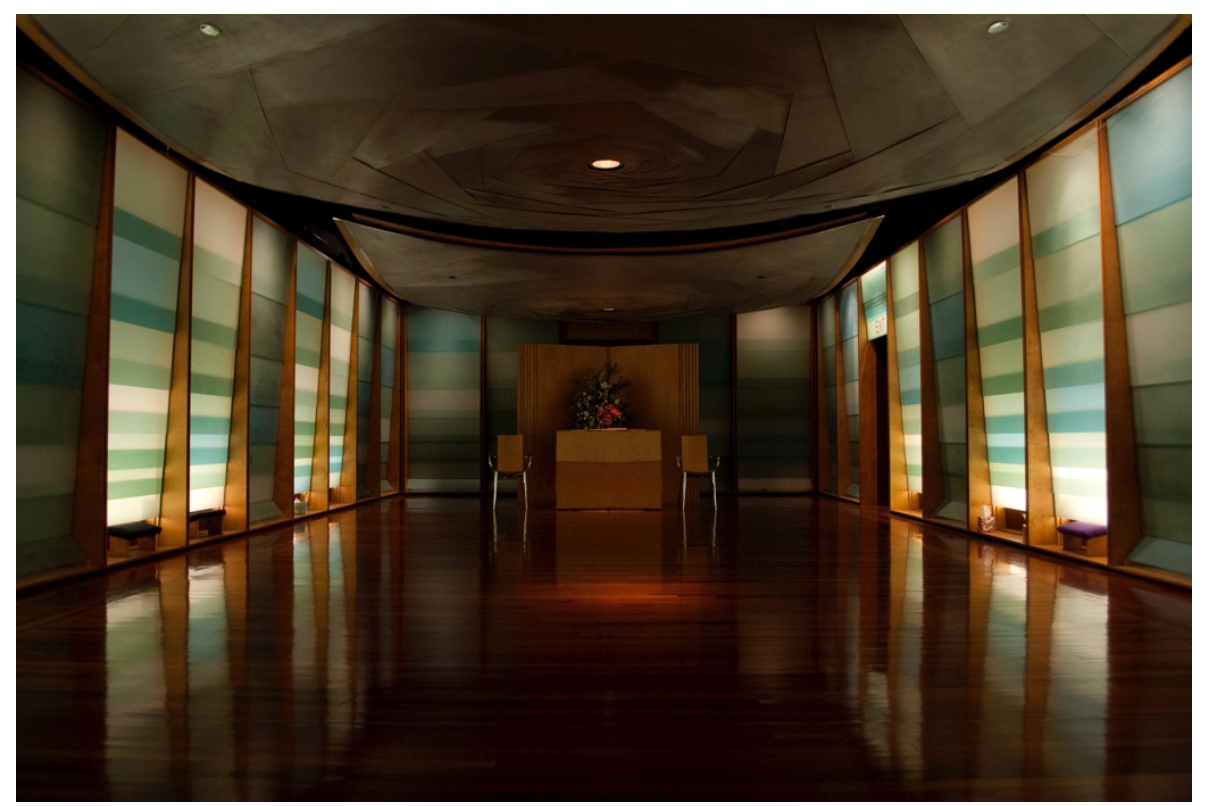

Figure 9: An inside view of the Interfaith Spiritual Centre of the Northeastern University in Boston, with the three concentric canopies, the artificial light hidden behind the side glass walls, colored with different shades of blue, and the continuous wooden pavement. (Yarian Gomez, www.bit.ly/324YH8n)

\section{In the end}

Rooted in a desire of sharing and understanding diversities, all these elements allow architecture to host different people, and people to feel welcomed: the relationship, of separation and inclusion together, with the outer world, the organization and distribution of the inner space, based also on a reasoned flexibility, the quality of building and finishing materials glimpsed in all the discussed case studies, the role played by natural and artificial light, and the one of works of art, traditional or not, as paintings, statues, light installations and videos. Somehow, the same words used in the vocabulary of confessional spaces, but declined in a new way.

20 Office dA, Interfaith Spiritual Centre, Northeastern University, Boston, Massachusetts, Usa 1999 (el-Khoury \& Riera Ojeda, 2000)

21 Kister Scheithauer Gross architekten und stadtplaner, Maria-Magdalena-Kirche, Freiburg, Germany 1998/2005 
Design culture should reason on these subjects and develop proper forms for them, looking at realized case studies and imaging new spaces, for at least two reasons. First of all, because diversity is one of the traits of contemporary society: people and traditions get close, boundaries weaken leaving space to thresholds, connecting differences. Then, because openness is a basic feature of architecture itself, able to create a significant relationship with the world, so that it can be lived as welcoming and life can be abundantly full of activities and meaning. This can happen only if designers understand and try to represent the identity and the aims of the society in which they live.

None of these spaces is white and neutral, a background receiving an identity from life interacting with it: all of them are perfectly designed as a hole and in detail, dense in meaning, and they are able to symbolize in universal words the relationship between man and God. They are real Architecture, that is a material form arise from the complex relationship between several components (Ottolini, 1997), in other word an integral, in the mathematical sense. ${ }^{22}$

In a 2003 interview, Ettore Sottsass told Anna Detheridge What really interests me is regaining an almost childish sense of wonder. I recently read some ancient Vedic texts where there appears to be a "pre-religious" sense of the world, and in which the divine plays an important role. We are inside this divine space. Day and night we are amazed by what happens, because we have no explanations - we simply open our eyes and wander through phenomena like children. (Sottsass, 2017)

Sacred architecture has to be built around this sense of wonder, deriving from the idea world and things within it, stay in the divine space, and among them stays human existence. The material forms of sacred architecture should become the medium through which this idea become clear and understandable, through which the rules underlying world becomes sharable and life rediscover a meaning, goyng beyond the ordinary and everyday life.

Non-confessional, shared, interfaith spaces more than many others, have the specific duty to discuss this topic in their designed and built forms, in their entrances, inviting communities to share experiences and mutual knowledge, in their rooms, variously declined depending on the different uses, and finally through their meaningful beauty.
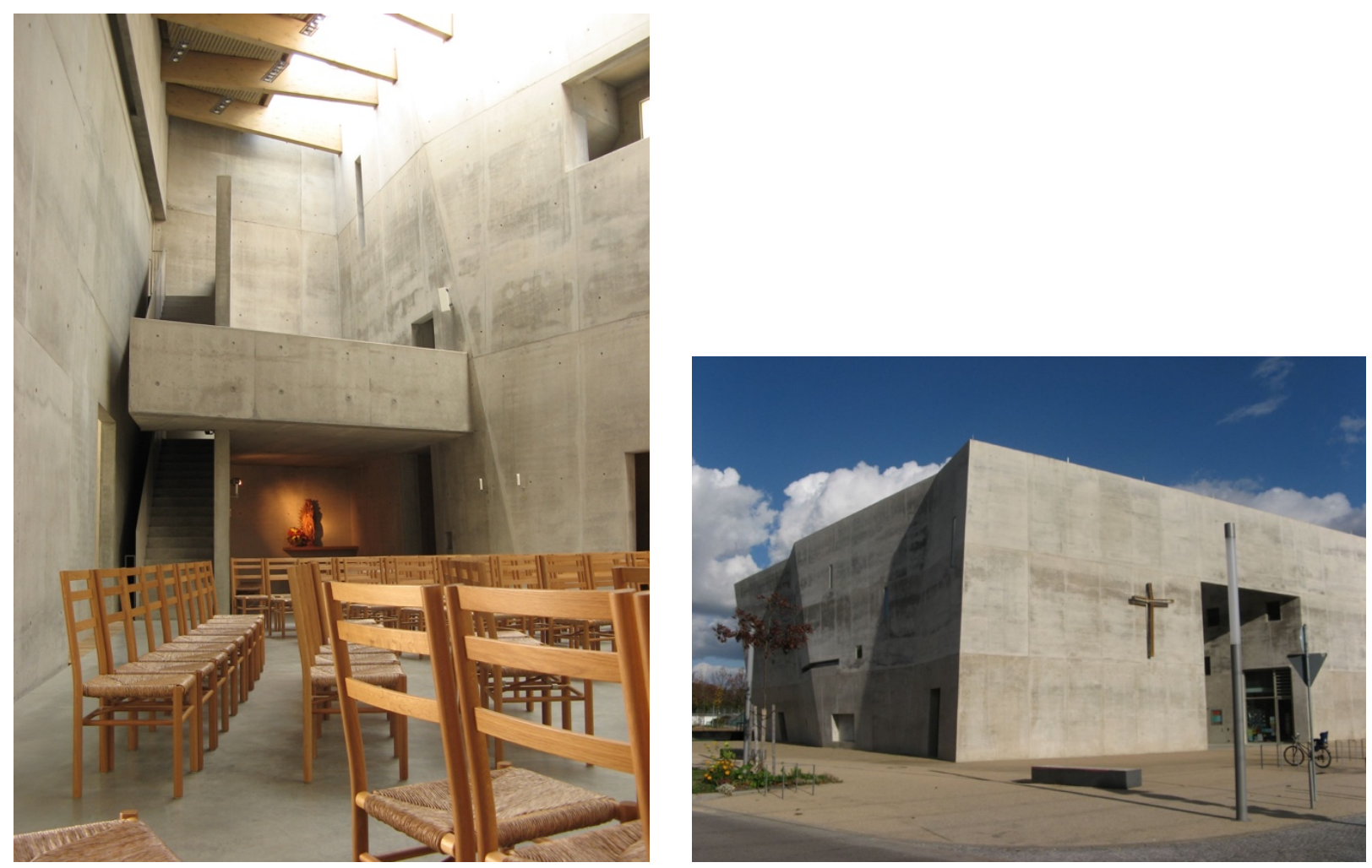

Figure 10: The essential and high interior of the Catholic Chapel inside the Maria-Magdalena-Kirche is lit only by the skylights opening over the level of the timber beams of the ceiling (grebrov, www. bit.ly/2NhKIbK)

Figure 11: The Maria-Magdalena-Kirche appears as a monolithic folded volume, with a few openings and the entrance in a high bay, leading to the shared inner space (grebrov, www. bit.ly/2J33kXK)

22 As stated by Biagio Garzena (Ottolini, 1997) 


\section{References}

Altan, C. T. (2002). Le grandi religioni a confronto. L'età della globalizzazione. Milano: Feltrinelli.

Boccaccio, G. (1470). Decameron. Napoli.

Boccaccio, G. (1855). Decameron or ten days' entertainment. (W. K. Kelly, A cura di) London: Henry G. Bohn. De Menil, D. (1971). The Rothko Chapel. Art Journal, 30(3), 249/251.

el-Khoury, R., \& Riera Ojeda, O. (2000). Office dA: works by Monica Ponce de Leon and Nader Tehrani. Gloucester, Mass.: Rockport.

Gattamorta, G., Rivalta, L., \& Savio, A. (1996). Louis I. Kahn. Itinerari. Roma: Officina Edizioni.

Haskell, B., \& Wortz, M. (1980). James Turrell: Light and space. New York: Whitney Museum of American Art.

Kahn, L. I. (1960, November 21). Structure and Form. Voice of America Forum Lectures, Architecture Series 6. Washington D.C., 1960.

Kompass Nelson, J. (1970). Harry Bertoia Sculptor. Detroit: Wayne State University.

Menocal, M. R. (2002), The Ornament of the World: how Muslims, Jews, and Christians created a culture of tolerance in medieval Spain, Boston: Little, Brown.

M.I.T. Chapel and Spire. (1955). Time Magazine.

Norberg-Schulz, C. (1985). The concept of dwelling: on the way to figurative architecture. New York: Rizzoli International Publications.

Ottolini, G. (1997). Forma e significato in architettura. Roma Bari: Laterza.

Powers, R. G. (1974, Summer). The Cold War in the Rockies: American Ideology and the Air Force Academy Design. Art Journal, 33(4), 304-313.

Rizzi, R. (2019, June 12). Gathering differences. Sacred space and diversities. Utopian and Sacred Architecture Studies. Aversa, CE, Italy

Russo, A. (2007). Lo spazio sacro nella città interetnica. Rassegna di Teologia (155), 403-420

Saarinen, E., \& Saarinen, A. B. (1968). Eero Saarinen on his work: a selection of buildings dating from 1947 to 1964 with statements by the architect. New Haven: Yale university press.

Serrazanetti, F., \& TAMassociati. (2017). Tamassociati: Taking care: architetture con emergency. Milano: Electa. Sorrentino, S. (2007). La grammatica del dialogo interreligioso. Per un approccio critico al rapporto fra le religioni. In S. Sorrentino, \& F. S. Festa, Le ragioni del dialogo. Grammatica del rapporto fra le religioni (p. 179-206). Troina: Città Aperta Edizioni.

Sottsass, E. (2017). There is a planet. Milano: Electa - Triennale Design Museum.

Tagliaferri, R. (1995). Lo spazio architettonico nell'esperienza religiosa. La mediazione spaziale della fede nel quadro della ritualità. In A. Piva, La città multietnica: lo spazio sacro (p. 50). Venezia: Marsilio Editori. 